Article

\title{
Gas Production from Gas Condensate Reservoirs Using Sustainable Environmentally Friendly Chemicals
}

\author{
Amjed M. Hassan ${ }^{1}{ }^{1}$, Mohamed A. Mahmoud ${ }^{1, *}$, Abdulaziz A. Al-Majed ${ }^{1}$, \\ Dhafer Al-Shehri $^{1}{ }^{(D}$, Ayman R. Al-Nakhli ${ }^{2}$ and Mohammed A. Bataweel ${ }^{2}$ \\ 1 College of Petroleum Engineering and Geosciences, King Fahd University of Petroleum \& Minerals, \\ Dhahran 31261, Saudi Arabia; amjed.moh06@gmail.com (A.M.H.); aamajed@kfupm.edu.sa (A.A.A.-M.); \\ alshehrida@kfupm.edu.sa (D.A.-S.) \\ 2 Saudi Aramco, Dhahran 31311, Saudi Arabia; ayman.nakhli@aramco.com (A.R.A.-N.); \\ MOHAMMED.BATAWEEL@ARAMCO.COM (M.A.B.) \\ * Correspondence: mmahmoud@kfupm.edu.sa
}

Received: 4 May 2019; Accepted: 15 May 2019; Published: 18 May 2019

check for updates

\begin{abstract}
Unconventional reservoirs have shown tremendous potential for energy supply for long-term applications. However, great challenges are associated with hydrocarbon production from these reservoirs. Recently, injection of thermochemical fluids has been introduced as a new environmentally friendly and cost-effective chemical for improving hydrocarbon production. This research aims to improve gas production from gas condensate reservoirs using environmentally friendly chemicals. Further, the impact of thermochemical treatment on changing the pore size distribution is studied. Several experiments were conducted, including chemical injection, routine core analysis, and nuclear magnetic resonance (NMR) measurements. The impact of thermochemical treatment in sustaining gas production from a tight gas reservoir was quantified. This study demonstrates that thermochemical treatment can create different types of fractures (single or multistaged fractures) based on the injection method. Thermochemical treatment can increase absolute permeability up to $500 \%$, reduce capillary pressure by $57 \%$, remove the accumulated liquids, and improve gas relative permeability by a factor of 1.2. The findings of this study can help to design a better thermochemical treatment for improving gas recovery. This study showed that thermochemical treatment is an effective method for sustaining gas production from tight gas reservoirs.
\end{abstract}

Keywords: gas production; gas condensate reservoirs; tight formations; thermochemical fluids

\section{Introduction}

Unconventional reservoirs have shown great potential for energy supply in long-term applications [1,2]. Shale and tight formations are common examples of unconventional resources, and they are considered as vast hydrocarbon resources based on their availability and the huge storage capacity [3]. However, great challenges are associated with hydrocarbon production from these reservoirs. Further, the primary recovery factors are less than $20 \%$, which implies the compelling need for advanced technologies. The low permeability of these reservoirs renders normal production methods unsuccessful [4-6]. Moreover, significant drawdown pressure is required to achieve economical production from these reservoirs. Therefore, horizontal drilling and multistage hydraulic fracturing technologies are extensively applied to improve the flow condition and increase the total gas production.

Drilling a horizontal well can increase the contact area between the wellbore and the reservoir. Then, the reservoir productivity will be improved, and considerable hydrocarbon can be produced [7]. Analytical and numerical models have been developed to estimate the performance of horizontal 
wells [8]. However, the main issue with drilling a horizontal well is that the drilling cost is much higher compared to that of vertical wells. Therefore, a hydraulic fracturing technique was developed to improve the productivity of unconventional reservoirs $[9,10]$. Longer conductive paths are created due to the fracturing treatment, which reduces the pressure drop and increases the hydrocarbon recovery. Franco et al. [11] reported a successful fracturing operation in a tight reservoir in Saudi Arabia. They mentioned that three stages of hydraulic fracturing can result in significant improvement in the reservoir productivity compared to the multilateral wells. The main concern with hydraulic fracturing is the environmental issues and the operational cost [12].

Pulse fracturing is a new effective method that can increase the stimulated reservoir volume (SRV) $[13,14]$. The operation is conducted by injecting fracturing fluids at different frequencies into the wellbore to create pressure pulses. The induced pulses will spread in the targeted formations and create a fracture network. The main advantage of pulse fracturing over conventional hydraulic fracturing is that lower injection pressure can be used in pulse fracturing. Furthermore, the generated fractures will propagate deeper in the case of pulse fracturing compared to normal hydraulic fracturing $[13,15,16]$. A new method of pulse fracturing was developed by Al-Nakhli et al. [17], where the fractures are generated using thermochemical fluids. The chemical reaction is triggered only at the downhole conditions using the reservoir temperature or chemical activator. The thermochemical reaction can generate a significant amount of heat and pressure in situ, and the induced pressure and temperature could reach $5000 \mathrm{psi}(34.5 \mathrm{MPa})$ and $700^{\circ} \mathrm{F}(644.3 \mathrm{~K})$, respectively [18].

Several approaches have been used to evaluate the changes in pore networks due to stimulation treatment [19]. One of these methods is nuclear magnetic resonance (NMR) measurement, which can be used to investigate variations in pore size distribution based on the profiles of T2 relaxation time. Figure 1 shows a typical NMR profile for sandstone and carbonate rocks. The T2 relaxation time is affected by three factors: Surface area, bulk volume, and fluid diffusion. The pore size is proportional to the surface area $(s)$ to volume ratio $(v)$ of the pores. Then, the T2 relaxation time can be used to study the changes of pore size distribution due to certain treatment. Smaller T2 relaxation time indicates fine pore space, while longer relation time means larger pore size [20]. The induced fractures are emulated based on the shift of the NMR T2 profile [21]. A shift of the relaxation time into the right side (higher relaxation times) indicates an improvement in rock conductivity, while if the T2 profile is shifted into the left side (lower relaxation times), that can indicate that damage has been induced into the considered rock. Usually, hydraulic fracturing treatment results in enlarging the pore sizes, and therefore, the NMR profile will be moved toward higher relaxation times [22]. In tight gas reservoirs, the sustainability of gas production can be quantified by studying the pore network. In general, changing the pore system of tight formations from isolated and small pores into a connected and large pore system can lead to enhancing and sustaining the hydrocarbon production from these types of reservoirs. 


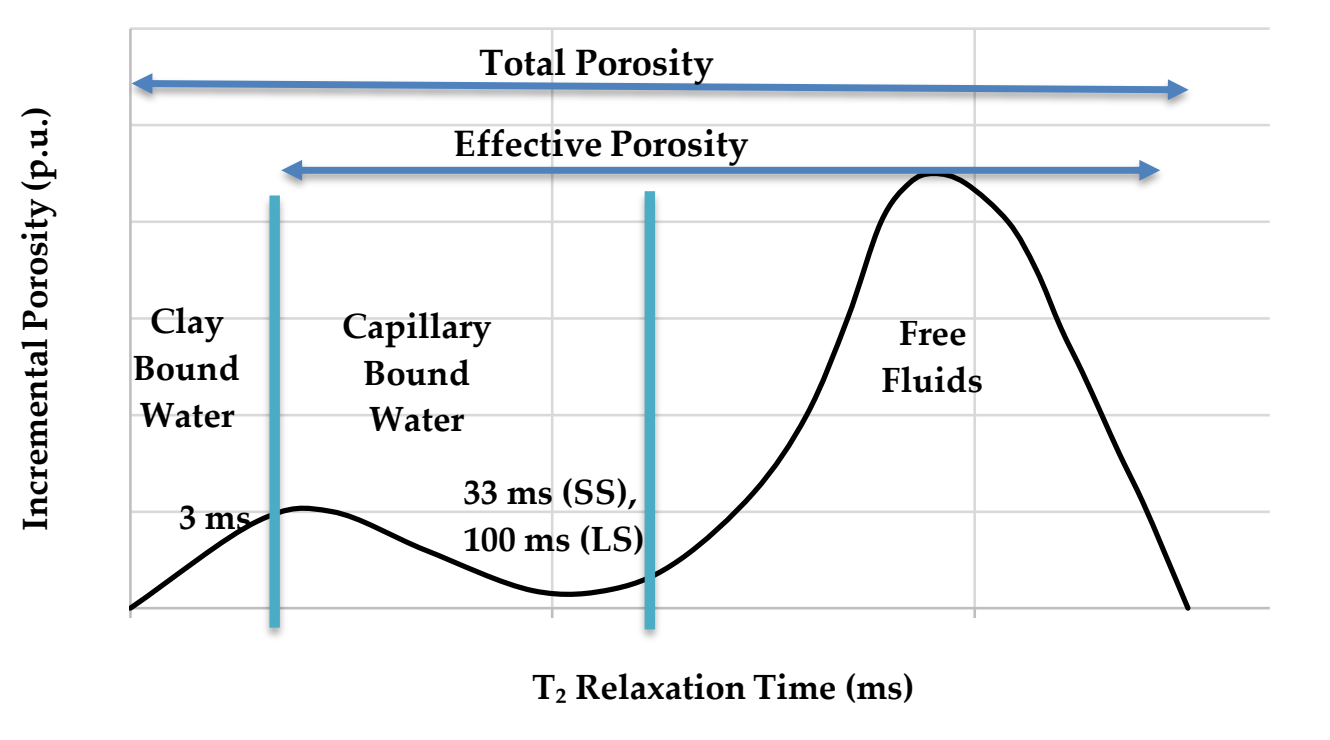

Figure 1. Typical nuclear magnetic resonance (NMR) interpretation model for sandstone (SS) and limestone (LS) rocks (replotted from Morriss et al. [23]).

In tight formations, the induced fractures can result in creating synthetic sweet spots in the treated regions and consequently increase the SRV. In gas reservoirs, the developed fractures improve the gas flow from the tight formation into the production well [24,25]. The conductivity of the chemically-induced fractures can be evaluated by determining the changes in the pore system due to the injected chemicals. Routine core analysis and NMR measurements can be utilized to quantify the improvement in rock conductivity due to the fracture creation. In the literature, alterations in the pore network due to thermochemical injections into tight formations is not fully understood. Further, the mechanisms behind generating different types of fractures (single or multifractures) is not completely studied. Therefore, this work would help in understanding the changes in pore size distribution due to thermochemical injection.

In a gas condensate reservoir, a liquid bank can be developed around the production well due to the pressure reduction below the dew point pressure. The accumulated liquids are immobile due to the low permeability and high capillary pressure of the tight formation. Therefore, the condensate liquid will accumulate around the production well and result in reducing the total gas production below the economic limits [26]. Different treatments are applied to remove the accumulated liquids and improve the gas production [27-29]. Gas and chemical injections are used to increase the pressure and change the phase behavior of liquid condensate; then, it can be easily produced through the production well. Moreover, hydraulic fracturing and horizontal wells are used to reduce the drawdown pressure and then delay the formulation of condensate liquid. Thermochemical treatment can be applied to remove the condensate bank. The generated heat and pressure due to the thermochemical reaction will change the condensate behavior. Further, the generated pressure can induce multifractures and reduce the capillary forces $[26,30]$.

The novelty of using thermochemical fluids for improving the gas production from gas condensate reservoirs is that the thermochemical treatment can induce a permanent improvement in the reservoir deliverability $[26,30]$. Thermochemical fluids are cheap, nontoxic, and environmentally friendly. Compared to the available techniques for enhancing the gas recovery, thermochemical treatment can reduce the operational cost up to $40 \%$ [30]. Further, the thermochemical reaction can be triggered only at the reservoir conditions, which maximizes treatment efficiency and minimizes energy loss into the surrounding formations [26]. Theoretically, thermochemical reaction can generate pressures up to $5000 \mathrm{psi}(34.5 \mathrm{MPa})$ and temperatures up to $700{ }^{\circ} \mathrm{F}(644.3 \mathrm{~K})$ [18]. Additionally, injection of 
thermochemical fluids into tight formations does not induce any damage into the reservoir rocks, and no reduction in the reservoir permeability or porosity was observed [30]. However, the main disadvantage of this treatment is that the generated pressure and heat can exceed the safe limit and may lead to undesired impacts. Therefore, this treatment should be well-designed by calculating the generated pressure and temperature due to the chemical reaction. Then, the treatment volume and the chemical concentration can be adjusted to achieve the required and safe amount of heat and pressure [26,30].

This paper discusses the experimental findings of NMR T2 measurements for a chemical stimulation method based on the induced pressure pulses using thermochemical fluids. The stimulation treatment is conducted utilizing the in situ generation of heat and pressure at downhole conditions to generate single and multifractures in tight formations. Therefore, it can increase the SRV and improve the total gas production from tight gas reservoirs. Actual tests of pulsed fracturing conducted in a laboratory scale using several core samples are presented. Multiple fractures and microfractures were created using the injection of thermochemical fluids into tight core samples. The increase in core porosity and permeability due to the chemical flooding is discussed. The alteration in pore geometry after the thermochemical treatment is evaluated. The effect of thermochemical injection on sustaining gas production from tight gas reservoirs is quantified. First, methodology is presented to describe the conduced experiments; coreflooding and NMR measurements were carried out. Then, the results of chemical injection and capillary pressure reduction are presented. Finally, the performance of thermochemical treatment in sustaining the gas production is discussed.

\section{Methodology}

In this work, thermochemical fluids were injected into different core samples to create fractures and improve core conductivity. The chemical reaction was triggered inside the treated core to generate heat and pressure pulse. The in situ generated temperature and pressure are significantly high and resulted in creating fractures in the used samples. Solutions of ammonium chloride $\left(\mathrm{NH}_{4} \mathrm{Cl}\right)$ and sodium nitrite $\left(\mathrm{NaNO}_{2}\right)$ were used as thermochemical fluids, and the chemical reaction was triggered using an acid. The chemical reaction during thermochemical injection can be represented by Equation (1) [18,26,27]:

$$
\mathrm{NH}_{4} \mathrm{Cl}+\mathrm{NaNO}_{2} \rightarrow \mathrm{NaCl}+2 \mathrm{H}_{2} \mathrm{O}+\mathrm{N}_{2} \text { (gas) }+\Delta \mathrm{H} \text { (heat) }
$$

Various analyses, including routine core analysis, chemical injection, and NMR measurements, were conducted using different rock samples. The changes in core characteristics were tracked by measuring the rock properties before and after the thermochemical treatment. Figure 2 shows the experimental setup used for the thermochemical treatment. The pressure-drop across the core sample was recorded to capture the generation of pressure pules due to the thermochemical injection. The changes in the pore network was determined using the $\mathrm{T} 2$ relaxation time. Table 1 lists the properties of the core samples used in this study. Figure 3 shows images for the core samples before and after the thermochemical treatment. 


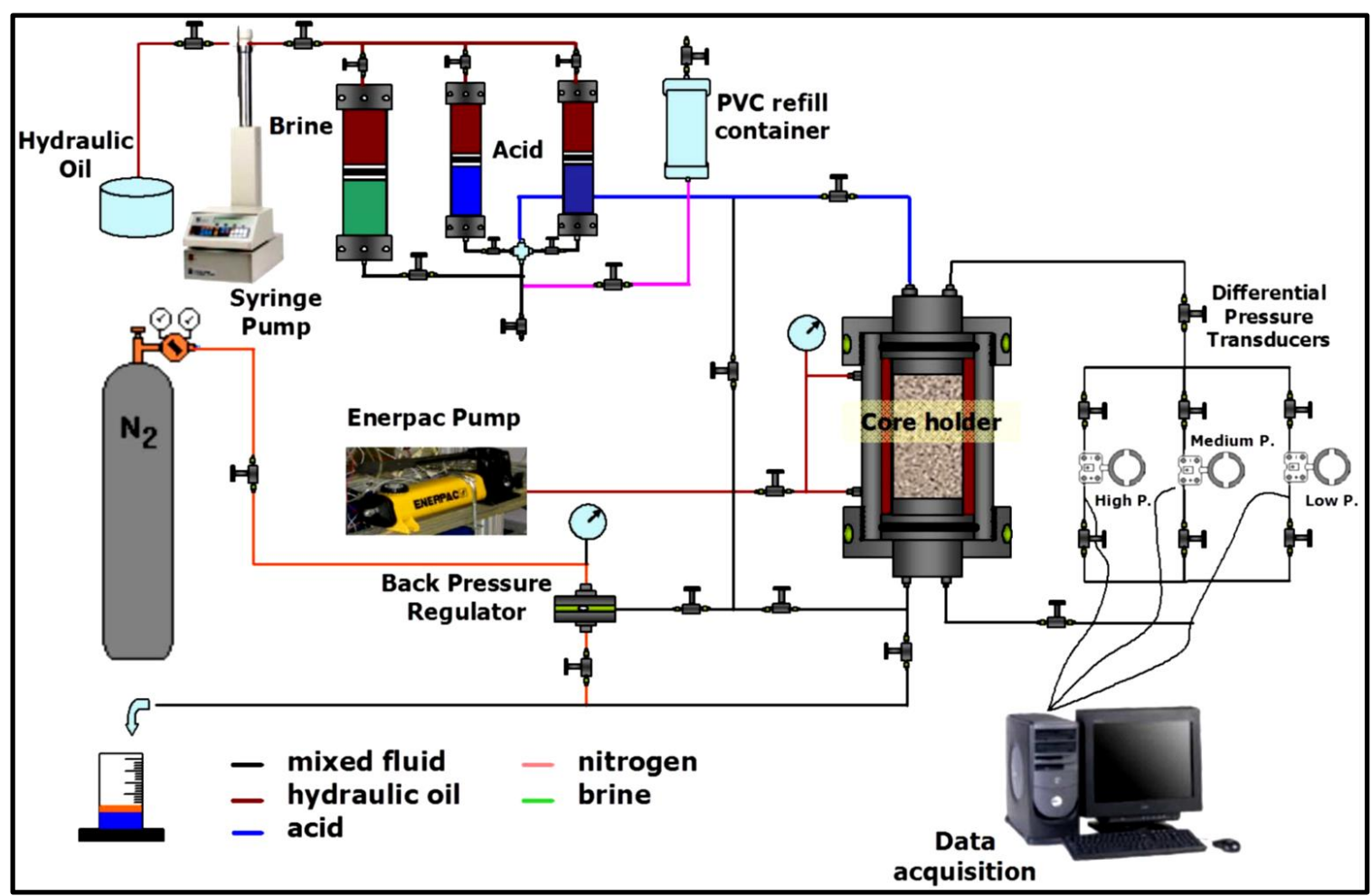

Figure 2. Schematic for the coreflooding setup used for thermochemical treatment (adapted from Alghamdi [28]).

Table 1. Rock properties of the core samples used in this work.

\begin{tabular}{|c|c|c|c|c|c|c|}
\hline Sample ID & $\begin{array}{l}\text { Diameter } \\
(\mathrm{cm})\end{array}$ & $\begin{array}{l}\text { Length } \\
(\mathrm{cm})\end{array}$ & $\begin{array}{c}\text { Bulk } \\
\text { Volume (ml) }\end{array}$ & $\begin{array}{c}\text { Pore } \\
\text { Volume }(\mathrm{ml})\end{array}$ & $\begin{array}{c}\text { Porosity } \\
(\%)\end{array}$ & $\begin{array}{r}\text { Absolut } \\
\text { Permeability }\end{array}$ \\
\hline 1 & 3.81 & 2.54 & 28.95 & 4.61 & 15.93 & 0.900 \\
\hline 2 & 3.81 & 5.179 & 58.374 & 8.067 & 13.82 & 1.096 \\
\hline 3 & 3.81 & 4.5 & 51.278 & 10.00 & 19.5 & 1.21 \\
\hline & Before treatr & & After treatment & & \multicolumn{2}{|c|}{$\begin{array}{c}\text { After treatment } \\
\text { (Top View) }\end{array}$} \\
\hline
\end{tabular}

Figure 3. Image for the core samples before and after the thermochemical treatment. 
Injection of thermochemical fluids into tight formation can change the relative permeability to hydrocarbon. Several models can be used to determine the relative permeability before and after the chemical treatment [31,32]. In this work, the Corey model (Equations (2) and (3)) [31,32] was used to estimate the improvement in gas effective permeability due to the injection of thermochemical fluids into tight rock samples.

$$
\begin{gathered}
k_{r o}=0.98372\left[\frac{S_{o}}{1-S_{w i}}\right]^{4}\left[\frac{S_{o}-S_{o r}}{1-S_{w i}-S_{o r}}\right]^{2} \\
k_{r g}=1.1072\left[\frac{S_{g}-S_{g c}}{1-S_{w i}}\right]^{2} K_{r o}+2.7794 S_{o r}\left[\frac{S_{g}-S_{g c}}{1-S_{w i}}\right] K_{r o}
\end{gathered}
$$

where $k_{r o}$ is the relative oil permeability (fraction), $S_{o}$ is the oil saturation (fraction), $S_{w i}$ is the irreducible water saturation (fraction), $S_{o r}$ is the residual oil saturation (fraction), $k_{r g}$ is the relative gas permeability (fraction), $S_{g}$ is the gas saturation (fraction), and $S_{g c}$ is the critical gas saturation (fraction).

\section{Results and Discussion}

Thermochemical fluids were injected into tight rock samples to create different types of fractures including single and multifractures and to improve the flow conductivity between the isolated pores. Several methods of injection were studied, including continuous flooding and cyclic injection of thermochemical fluids. The main goals for all experiments are to maximize the size of the generated fractures, increase the fracture propagation in the treated samples, and reduce the amount of thermochemical fluids to be injected. For all samples, the improvement in core permeability and porosity were estimated using the profiles of pressure-drop across the core samples and the pore size distribution, respectively. Further, NMR measurements were performed before and after the stimulation treatment to determine the changes in pore sizes distribution due to the thermochemical treatment. The alterations in the pore network were analyzed based on the shift of T2 relaxation time after the chemical injection.

\subsection{Batch Chemical Injection}

Tight sandstone samples were treated with the thermochemical fluids to induce single fractures. The chemical solutions were injected as one batch, then, they allowed reacting and generating pressure pulses. The pore pressure was monitored to capture the pressure pulses. The changes in core properties was determined using permeability and porosity measurements as well as the NMR analysis. During the thermochemical treatment, the pore pressure increased quickly to more than $11 \mathrm{MPa}$ (Figure 4). The pressure increment is attributed mainly to the thermochemical reaction, which was generated inside the treated core. Consequently, a single fracture was induced in the tight core sample due to the stimulation treatment. The rock properties were changed considerably after the chemical injection, the core permeability increasing by $10 \%$ and the porosity increasing by $5 \%$. The increase of core permeability was only $10 \%$, and this was due to the injection of a single batch of thermochemical fluids; however, cyclic injection of chemical solutions can lead to huge improvement in the absolute permeability, as will be discussed in Sections 3.2 and 3.3.

Figure 5 shows the T2 profiles for the core sample before and after the thermochemical treatment. The relaxation time confirms the fracture generation after the chemical stimulation process. The T2 profile was shifted toward the higher relaxation time, indicating that the fracture was created due to the thermochemical treatment. The fracture was induced as a result of the pressure pulse that was generated inside the core sample, due to the thermochemical reaction. The sudden increase in pore pressure from 1 to $11 \mathrm{MPa}$ led to creating a tiny fracture in the treated core sample. 


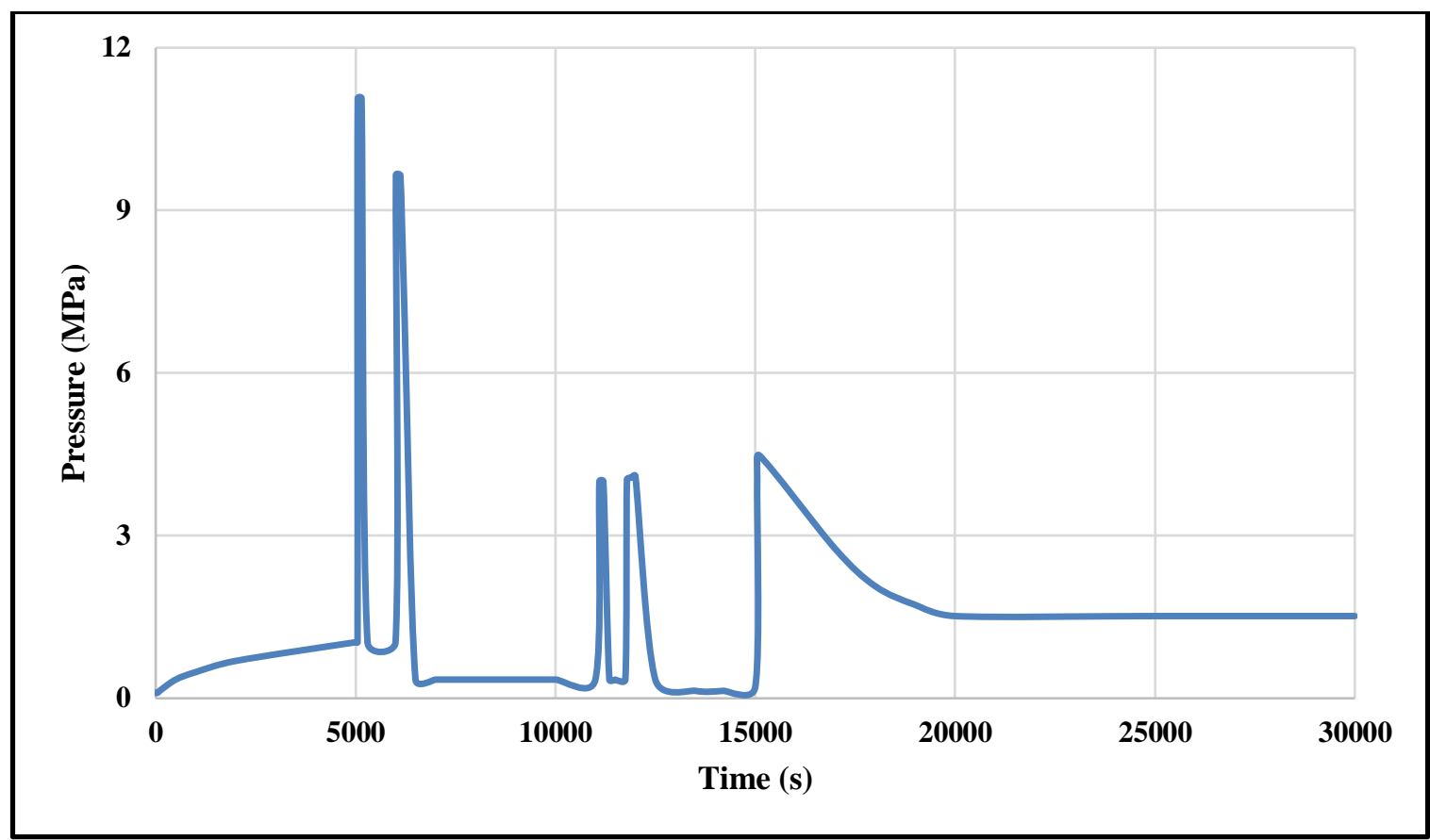

Figure 4. Profile of pore pressure during thermochemical treatment. Pressure pulses were in situ generated due to the thermochemical reaction.

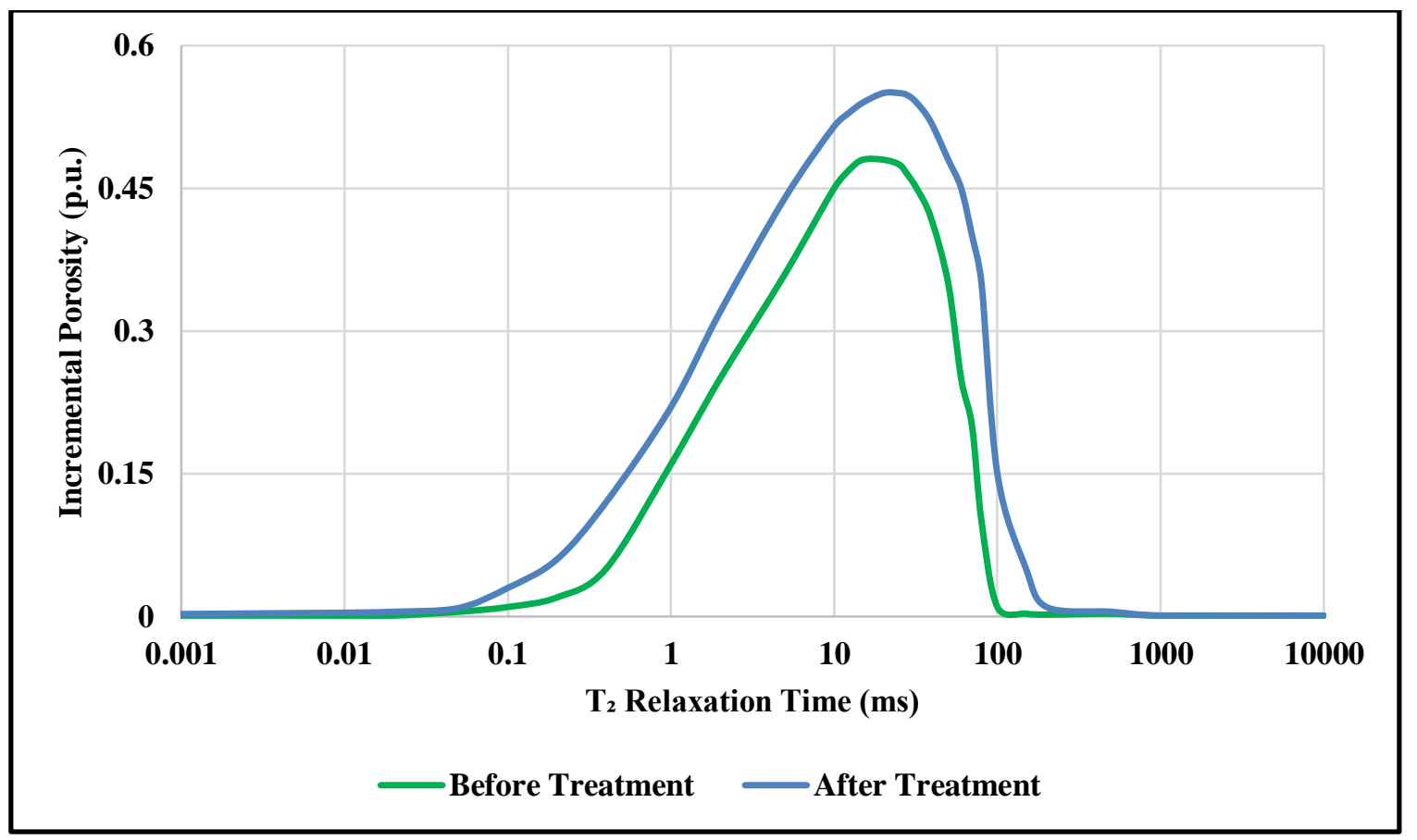

Figure 5. Profile of relaxation time before and after the thermochemical injection into the tight sandstone sample. The relaxation time was shifted to higher time after the treatment.

\subsection{Cyclic Injection of Thermochemical Fluids}

Figure 6 shows the profiles of pressure-drop across the core sample during thermochemical treatment. Cyclic injection of thermochemical fluids was applied into tight sandstone samples. The pore pressure increased significantly due to the thermochemical reaction; a pressure of $13 \mathrm{MPa}$ was observed at the core inlet. Four cycles of chemical injections were applied to alter the rock properties and generate fractures. Considerable fractures were induced in the treated sample due to the pressure 
pulses. During the first cycle, the pore pressure increased to $6.1 \mathrm{MPa}$, while it was raised to more than 12.4 MPa during the second and third cycles of thermochemical injection. In all phases, the pressures at core inlet and outlet are almost same, which indicates uniform pressure distribution along the treated core sample.

NMR was used to evaluate the changes in pore size distribution due to the thermochemical injection. Figure 7 shows the T2 distribution for the core sample before and after the thermochemical treatment. The cyclic injection of thermochemical fluids resulted in creating multiractures. The induced fractures were indicated by the shift of $\mathrm{T} 2$ relaxation time toward the higher pore sizes (right side). In this treatment, the generated fractures led to changing the porosity model from a unimodel into a dual porosity system. Those fractures were developed due to the rapid increase in the pore pressure when the thermochemical reaction was activated. Injecting thermochemical fluids in four cycles led to increasing the amount and the density of generated fractures. More fractures were observed close to the injection point, while a smaller amount of fractures was noticed at the core outlet. This fracture distribution was expected, since the chemical reaction will occur close to the injection side; then, the generated pressure waves will transfer away from the reaction point.

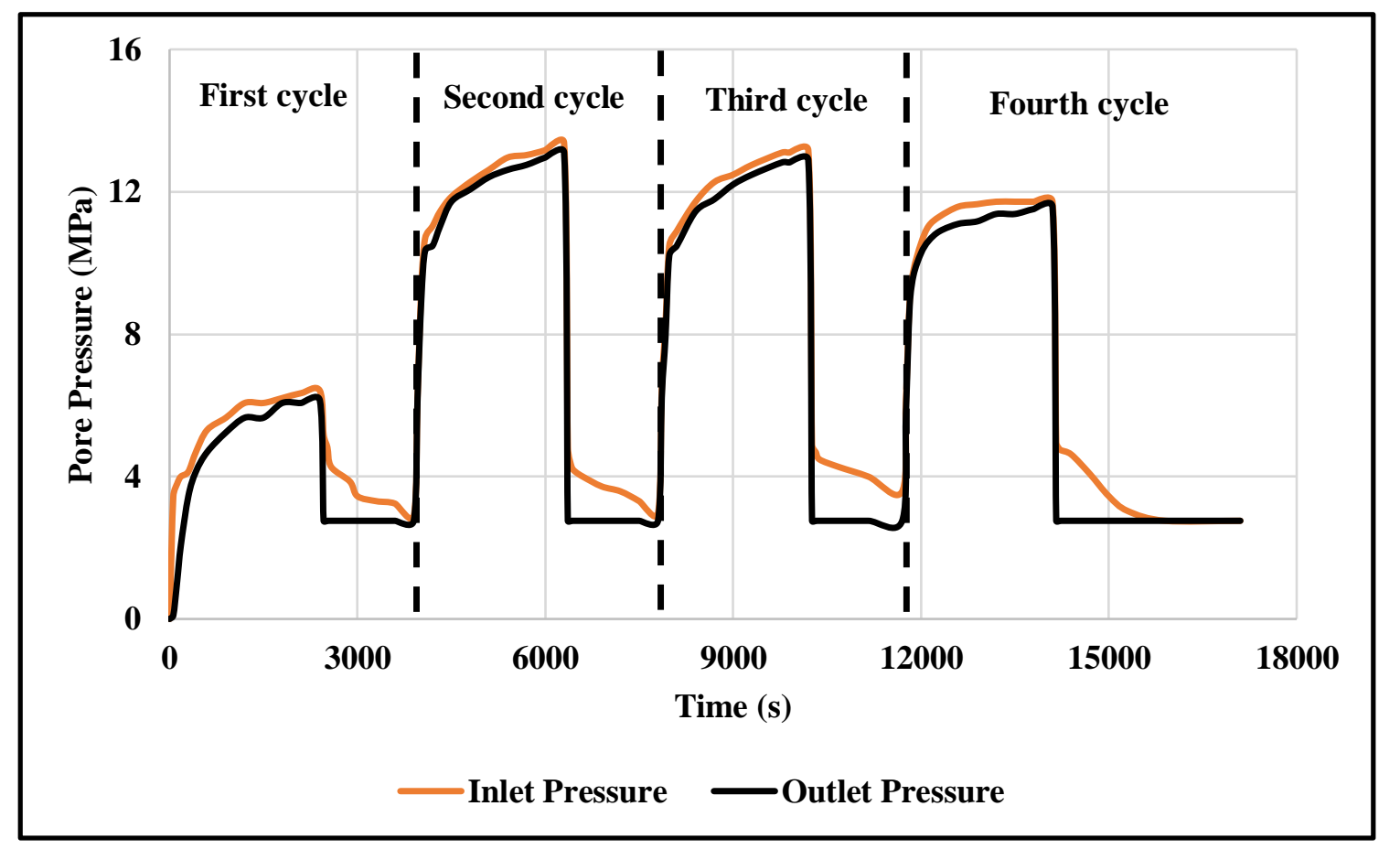

Figure 6. Cyclic injection of thermochemical fluids into tight sandstone samples. The pressure increased rapidly from 2.7 to $13.1 \mathrm{MPa}$; the pressure pulse created fractures in the treated rock. 


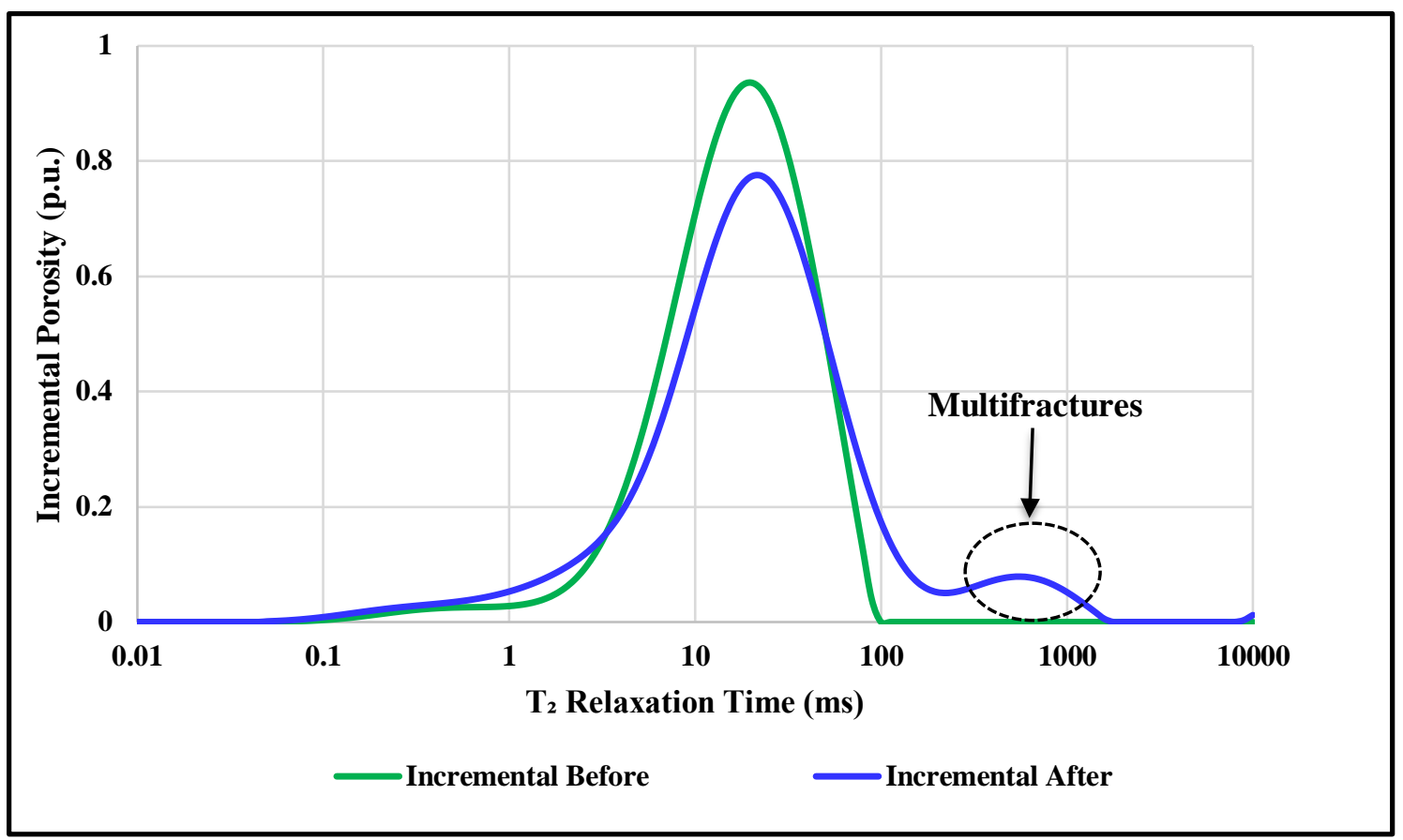

Figure 7. T2 distribution for the core sample before and after thermochemical injection. Multifractures were generated after the chemical treatment, and the porosity model was changed to a dual porosity system.

\subsection{Continuous Thermochemical Injection}

The heterogeneity of reservoir formation restricts hydrocarbon production due to the poor communication between the pores that contain hydrocarbon. Thermochemical fluids were injected continuously into rock samples to enhance the formation conductivity, by connecting and enlarging the isolated and small pores. Figure 8 shows the pressure drop across the core sample during thermochemical injection. The core permeability was measured before and after the treatment; the core has average permeability of 1.21 and $7.28 \mathrm{mD}$ before and after the stimulation treatment, respectively. The thermochemical fluids were injected into the rock samples at a constant flow rate of $1 \mathrm{~cm} 3 / \mathrm{min}$, and the treatment period was 60 mins. The pressure-drop decreased significantly after the thermochemical injection, indicating the enhancement of core conductivity. The reduction in pressure-drop across the treated core sample is $87 \%$; the stabilized pressure-drops are 15.9 and $2.1 \mathrm{KPa}$ before and after the treatment, respectively.

The porosity distribution profiles were obtained before and after the thermochemical treatment using NMR measurement. Figure 9 shows the profiles of T2 relaxation time before and after the chemical injection. Isolated systems of micro-, miso-, and macropores were observed pretreatment, which resulted in reducing the communication between the different pore systems, while after the treatment, a single curve of relaxation time was observed, which reveals that the pore system was changed from a triple (isolated) pore system into a connected porosity system. Further, flooding the core samples with thermochemical fluids led to increasing the portion of macropores significantly, as presented in Figure 9. The NMR profile for the macropores was shifted up after the thermochemical treatment. The change of pore network from a triple (isolated) model into a dual (connected) porosity system can lead to enhancing the pore connection between all of the micro-, miso-, and macropores. Consequently, gas production will significantly increase due to the thermochemical injection. After the thermochemical treatment, absolute permeability was increased by $502 \%$; the values of core permeability pre- and post-treatment were 1.21 and $7.28 \mathrm{mD}$, respectively. This improvement in absolute permeability confirms the enhancement of core conductivity due to the thermochemical injection. Ultimately, injecting thermochemical fluids into a heterogeneous formation can lead to 
improving the pore connection, increasing the formation permeability and, therefore, enhancing and sustaining hydrocarbon production.

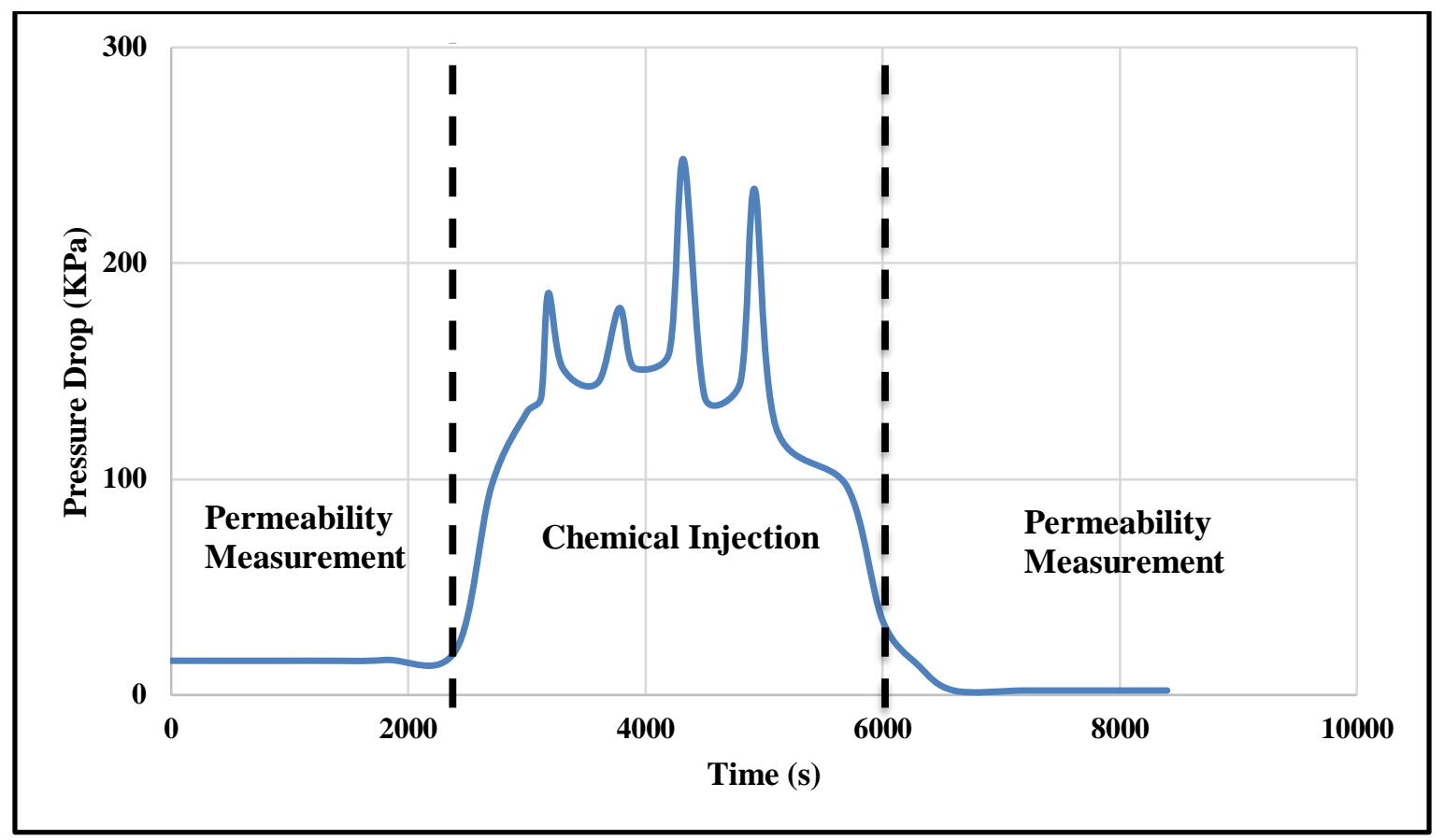

Figure 8. Profile of pressure-drop across the treated core sample during the thermochemical injection. The pressure-drop reduced by $87 \%$ due to the chemical treatment.

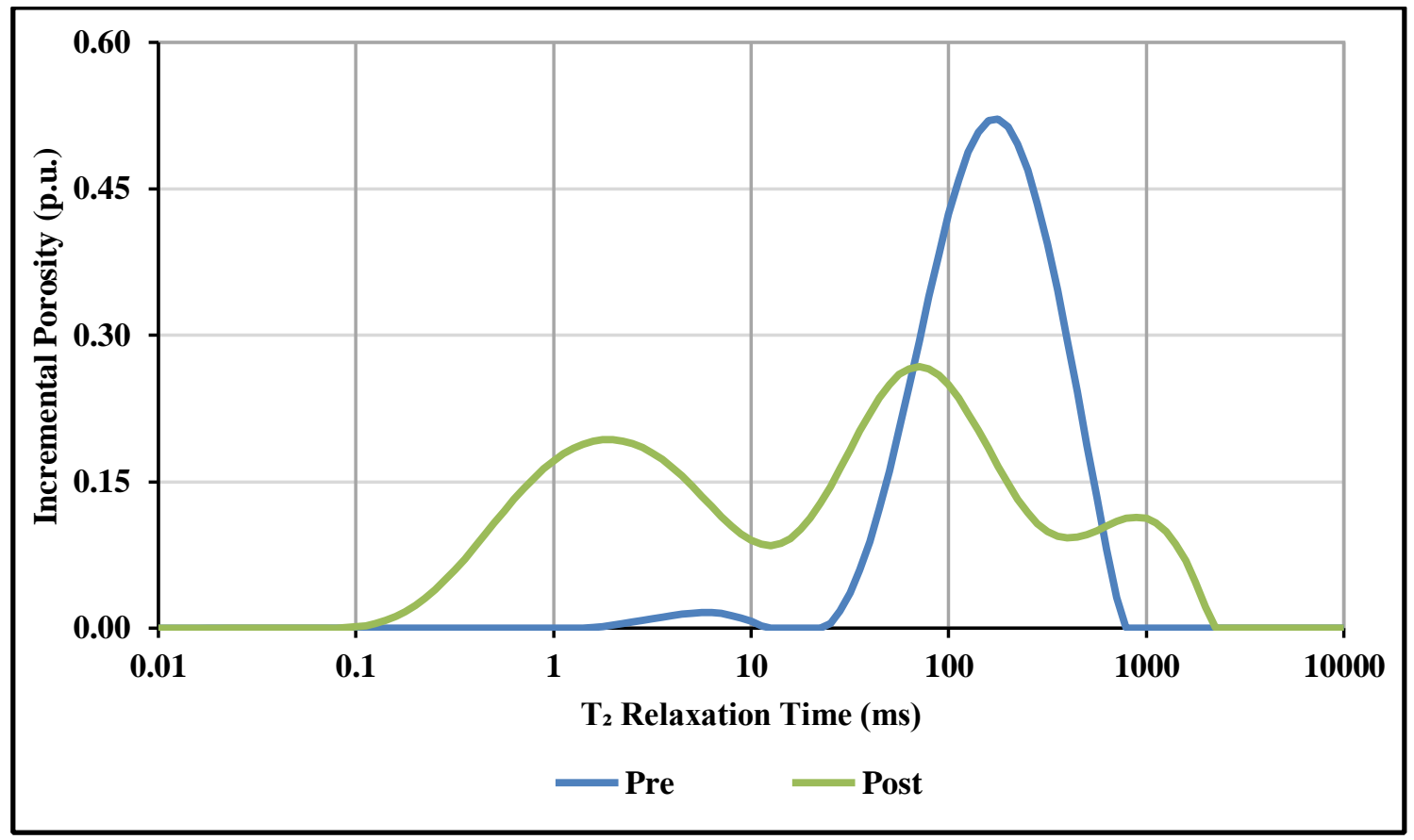

Figure 9. Profiles of T2 relaxation time before and after the treatment. The pore network was changed from an isolated triple pore system into a connected porosity model after the treatment, which will enhance the core conductivity.

\subsection{Capillary Pressure Enhancement}

The capillary pressure is one of the critical issues in producing hydrocarbon from a tight reservoir, because tight reservoirs are characterized by significantly high capillary pressure due to the ultra-low 
formation permeability. Due to the low permeability and the high capillary pressure, fluids (such as water of condensate) can accumulate around the production wells and result in significant reduction in the total hydrocarbon production. Therefore, most of the treatments applied in the tight reservoir are aiming to increase the formation permeability and improve the flow condition. Increasing the absolute permeability of tight formation can lead to reducing the capillary pressure, and then, more hydrocarbon can be produced. In this work, injection of thermochemical fluids into tight core samples showed a considerable increase in the core permeability; the permeability enhancement reached $500 \%$ in the case of ultra heterogeneous rock, as discussed in Section 3.3. The improvement of core permeability is mainly attributed to the generation of single or multifractures due to the in situ generation of pressure pulses inside the treated rock samples. The induced fractures in tight formation, due to thermochemical injection, showed significant reduction in capillary pressure. Figure 10 shows the capillary pressure curves before and after the thermochemical treatment. The capillary pressure reduced by $57.2 \%$ due to the injection of thermochemical fluids into the tight rock sample; the capillary pressures were $62.7 \mathrm{KPa}$ and $26.9 \mathrm{KPa}$, before and after the thermochemical treatment, respectively. In gas condensate reservoirs, the enhancement of the capillary condition can lead to removing the accumulated fluids from the near-wellbore region, and consequently improving gas deliverability.

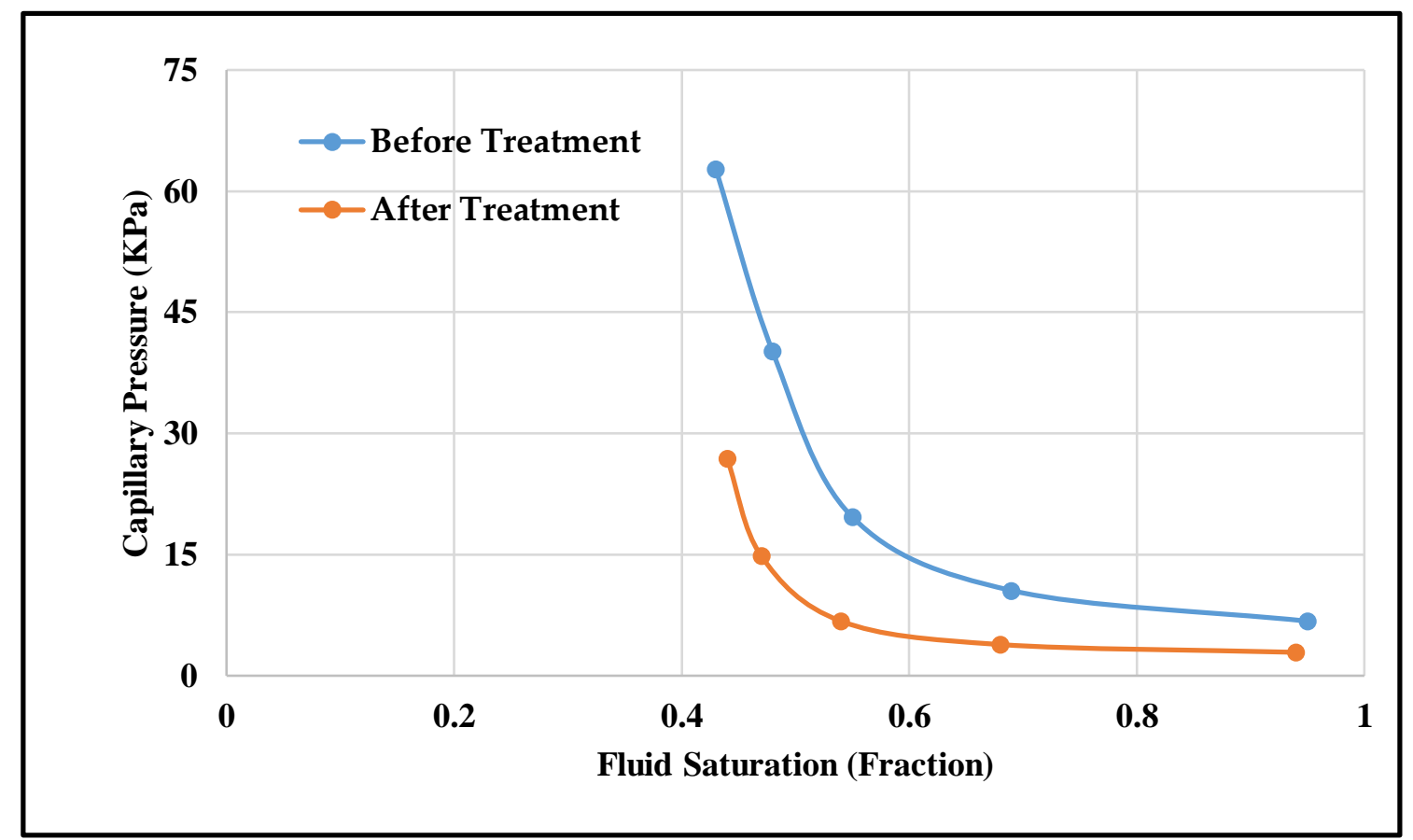

Figure 10. Profiles of capillary pressure before and after the thermochemical treatment. The capillary pressure decreased by $57.2 \%$ due to thermochemical injection into the tight rock sample.

\subsection{Gas Production Improvement}

In a gas condensate reservoir, the reduction of reservoir pressure results in liquid drop-out, which can accumulate around the production well and create a condensate blockage. The condensate bank reduces the effective permeability to gas, and then, the total gas production will be dramatically decreased [29]. Injection of thermochemical fluids into gas condensate reservoirs can result in enhancing hydrocarbon production utilizing several mechanisms. The injected chemicals are able to generate a significant amount of heat and pressure at the reservoir condition; the generated heat and pressure can reach to $644.3 \mathrm{~K}$ and $34.5 \mathrm{MPa}[18,26]$. The induced heat and pressure change the behavior of the condensate liquid. The viscosity of the condensate liquid can be reduced by 10 times due to the in situ generation of heat at the reservoir condition [26,30]. Further, the generated pressure can create single or multifractures around the treated well. The induced fractures lead to reducing the capillary forces 
that hold the condensate liquids in the region around the wellbore; thus, the accumulated condensate can easily flow into the borehole. Removal of the condensate bank will improve gas production from gas condensate reservoirs by improving the effective permeability to gas. The Corey model (Equations (2) and (3)) was used to estimate the improvement in gas effective permeability due to the injection of thermochemical fluids [31,32].

Figure 11 shows the effect of thermochemical treatment on enhancing gas relative permeability. Injection of thermochemical fluid improved the relative permeability of gas by a factor of 1.2; the relative gas permeability increased from 0.759 to 0.927 after the thermochemical treatment. The increase in gas relative permeability is attributed mainly to the generation of multifractures and the reduction of capillary pressure. Ultimately, injection of thermochemical fluids into gas condensate reservoir can induce a permanent improvement in the flow condition, by reducing the capillary pressure and removing the condensate banking. Consequently, the thermochemical treatment can sustain gas production from gas condensate reservoirs by enhancing the effective gas permeability for long-time operations.

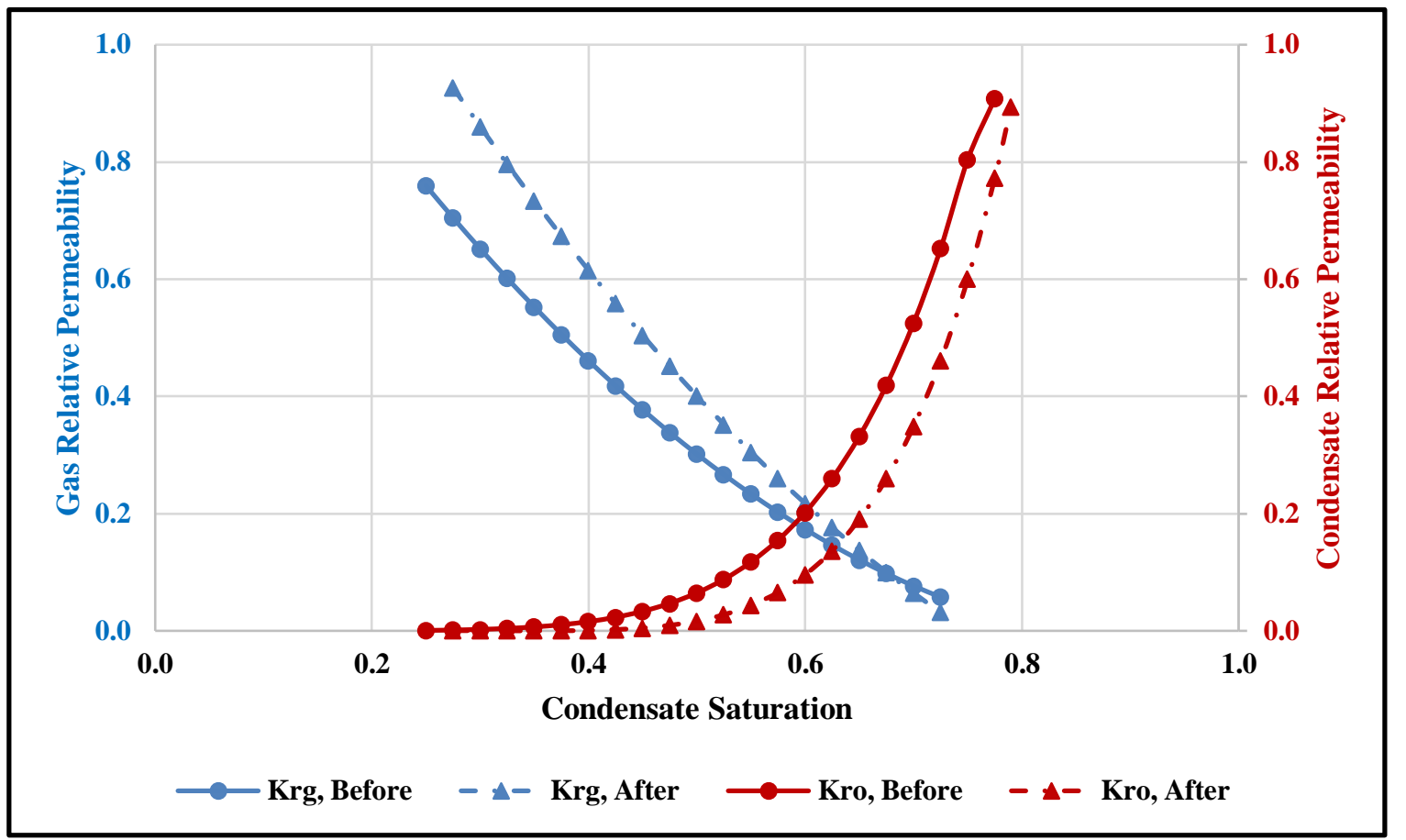

Figure 11. Effect of thermochemical injection on enhancing gas relative permeability. Gas permeability is improved by a factor of 1.2, which can sustain gas production for long-time operations.

Comparing the performance of thermochemical treatment with the other methods of improving gas production from a gas condensate reservoir, such as solvent or carbon dioxide $\left(\mathrm{CO}_{2}\right)$ injection, shows that thermochemical treatment has several advantages over the current methods. The thermochemical fluids are non-expensive, nontoxic, and environmentally friendly. Injection of thermochemical fluids can lead to significant reduction in the operational cost, because the treatment can be applied and focused only at the target zone, which minimizes the amount of chemicals used during the operations. Further, the in situ generation of heat and pressure at the reservoir condition can minimize the impact of the stimulation treatment on the integrity of well completion. Finally, thermochemical treatment leads to permanent improvement in the hydrocarbon production, while $\mathrm{CO}_{2}$ or solvent injection are considered as temporary methods for increasing hydrocarbon production [33].

This work was carried out at laboratory scale, where core samples and a small volume of thermochemical fluids were used. However, this study can be further extended by applying the thermochemical treatment at field scale. A good candidate for this treatment can be a gas well that 
has a low production rate due to the condensate damage. Thermochemical fluids can be injected into the gas production well to increase temperature and pressure around the wellbore and consequently affect the condensate behavior. The treatment duration and the injected volume can be selected based on the radius of condensate liquid. The duration and injected volume will increase as the radius of condensate region increases. Finally, the performance of thermochemical treatment can be compared with the performance of other methods, such as solvent or gas injection.

\section{Conclusions}

Great challenges are associated with sustaining gas production from gas condensate reservoirs. Injection of thermochemical fluids has been introduced as a new and cost-effective technique for stimulating tight reservoirs. In this paper, the impact of thermochemical injection on sustaining gas production from gas condensate reservoir was discussed. Further, the alteration of a pore network due to thermochemical treatment was evaluated using coreflooding experiments and NMR measurements. This study demonstrates that thermochemical treatment can create different types of fractures (single or multistaged fractures) based on the injection method. Batch, continuous or cyclic injection of thermochemical fluids can be applied. The pressure pulse generated due to the thermochemical reaction can induce fractures in the tight sandstone formations. Single and multifractures were observed in the treated rock samples after the batch and cyclic injection of thermochemical fluids, respectively. Flooding the heterogeneous formation with thermochemical fluids can result in improving the formation conductivity, by connecting the isolated pores (micro-, miso-, and macropores), and consequently increase the absolute permeability. In all treated samples, the absolute permeabilities were increased after the thermochemical treatment. Permeability improvements of $10 \%$ and $502 \%$ were achieved using the batch and continuous injection of thermochemical fluids, respectively. Based on this study, the advantages of applying thermochemical treatment are generating the pressure pulses only inside the targeted zone and then minimizing energy losses. Thermochemical injection reduces capillary pressure by $57 \%$, removes the accumulated liquids, and improves gas relative permeability by a factor of 1.2. Ultimately, injection of thermochemical fluids into tight and heterogeneous reservoirs can result in improving pore conductivity and increasing formation permeability, and consequently enhances and sustains hydrocarbon production.

Author Contributions: Formal analysis, M.A.M.; Investigation, D.A.-S.; Methodology, A.A.A.-M.; Supervision, M.A.M.; Validation, A.R.A.-N.; Visualization, M.A.B.; Writing一original draft, A.M.H.

Funding: This research was funded by Saudi Aramco, grant number CIPR2317.

Acknowledgments: The college of Petroleum and Geoscience, at King Fahd University of Petroleum \& Minerals, and Saudi Aramco are acknowledged for the support and permission to publish this work. Saudi Aramco is also acknowledged for funding this research under project number CIPR2317. Authors are grateful to Syed Rizwanullah for conducting the NMR measurements. We also thank Abdulrauf Adebayo for approval to access the NMR equipment at the Center for Integrative Petroleum Research (CIPR)-CPG, KFUPM.

Conflicts of Interest: The authors declare no conflict of interest.

\section{References}

1. Guo, K.; Zhang, B.; Aleklett, K.; Höök, M. Production patterns of Eagle Ford shale gas: Decline curve analysis using 1084 wells. Sustainability 2016, 8, 973. [CrossRef]

2. Liu, H.; Li, J. The US Shale Gas Revolution and Its Externality on Crude Oil Prices: A Counterfactual Analysis. Sustainability 2018, 10, 697.

3. Xiao, J.; Wang, X.; Wang, R. Research on Factors Affecting the Optimal Exploitation of Natural Gas Resources in China. Sustainability 2016, 8, 435. [CrossRef]

4. Bennion, D.B.; Bietz, R.F.; Thomas, F.B.; Cimolai, M.P. Reductions in the productivity of oil and low permeability gas reservoirs due to aqueous phase trapping. J. Can. Pet. Technol. 1994, 33. [CrossRef] 
5. Bennion, D.B.; Thomas, F.B.; Bietz, R.F. Low Permeability Gas Reservoirs: Problems, Opportunities and Solutions for Drilling, Completion, Stimulation and Production. In Proceedings of the SPE Gas Technology Symposium, Calgary, AB, Canada, 28 April-1 May 1996. SPE 35577.

6. Fairhurst, D.L.; Indriati, S.; Reynolds, B.W.; Lewis, J.W.; Holcomb, M.W.; Starr, F.F. Advanced technology completion strategies for marginal tight gas sand reservoirs: A production optimization case study in South Texas. In Proceedings of the SPE Annual Technical Conference and Exhibition, Anaheim, CA, USA, 1-14 November 2007. SPE 109863.

7. Ghahri, P.; Jamiolahmadi, M.; Alatefi, E.; Wilkinson, D.; Dehkordi, F.S.; Hamidi, H. A new and simple model for the prediction of horizontal well productivity in gas condensate reservoirs. Fuel 2018, 223, 431-450. [CrossRef]

8. Miller, N.; Nasrabadi, H.; Zhu, D. On application of horizontal wells to reduce condensate blockage in gas condensate reservoirs. In Proceedings of the International Oil and Gas Conference and Exhibition in China, Beijing, China, 8-10 June 2010. SPE-130996-MS.

9. Feng, X.; Ma, F.; Zhao, H.; Liu, G.; Guo, J. Gas Multiple Flow Mechanisms and Apparent Permeability Evaluation in Shale Reservoirs. Sustainability 2019, 11, 2114. [CrossRef]

10. Wu, X.; Xia, J.; Guan, B.; Yan, X.; Zou, L.; Liu, P.; Yang, L.; Hong, S.; Hu, S. Water Availability Assessment of Shale Gas Production in the Weiyuan Play, China. Sustainability 2019, 11, 940. [CrossRef]

11. Franco, C.A.; Solares, J.R.; Asiri, K.S.; Shammari, N.; Alabbad, E.A.; Gomez, A.; Antonio, F. Optimization of conventional acid jobs and the historical trend leading to multi-stage acid fracturing stimulation to increase gas-condensate productivity in carbonate reservoirs in saudi Arabia. In Proceedings of the SPE Middle East Oil and Gas Show and Conference, Manama, Bahrain, 25-28 September 2011.

12. EPA. Hydraulic Fracturing for Oil and Gas: Impacts from the Hydraulic Fracturing Water Cycle on Drinking Water Resources in the United States, Executive Summary; EPA: Washington, DC, USA, 2018.

13. Xu, J.; Zhai, C.; Qin, L. Mechanism and application of pulse hydraulic fracturing in improving drainage of coalbed methane. J. Nat. Gas Sci. Eng. 2017, 40, 79-90. [CrossRef]

14. Mustafa, A.; Tariq, Z.; Abdulraheem, A.; Mahmoud, M.; Al Nakhli, A.; BaTaweel, M. Increasing stimulated reservoir volume srv in unconventional reservoirs: microstructural and rock mechanical study. In Proceedings of the Abu Dhabi International Petroleum Exhibition \& Conference, Abu Dhabi, UAE, 12-15 November 2018.

15. Page, J.C.; Miskimins, J.L. A comparison of hydraulic and propellant fracture propagation in a shale gas reservoir. In Proceedings of the Canadian International Petroleum Conference, Calgary, AB, Canada, 17-19 June 2008.

16. Wu, J.J.; Liu, L.C.; Zhao, G.H.; Chu, X.S. Research and exploration of high energy gas fracturing stimulation integrated technology in Chinese shale gas reservoir. Adv. Mater. Res. 2012, 524, 1532-1536. [CrossRef]

17. Al-Nakhli, A.R.; Abass, H.; Kwak, H.T.; Al-Badairy, H.; Al-Ajwad, H.A.; Al-Harith, A.; Al-Otaibi, A. Overcoming unconventional gas challenges by creating synthetic sweetspot and increasing drainage area. In Proceedings of the SPE Middle East Oil and Gas Show and Conference, Manama, Bahrain, 10-13 March 2013.

18. Al-Nakhli, A.R.; Sukkar, L.A.; Arukhe, J.; Mulhem, A.; Mohannad, A.; Ayub, M.; Arifin, M. In-Situ steam generation a new technology application for heavy oil production. In Proceedings of the SPE Heavy Oil Conference and Exhibition; SPE 184118, presented at the SPE Heavy Oil Conference and Exhibition, Kuwait City, Kuwait, 6-8 December 2016.

19. Castiblanco, R.; Ibrahim, E.G.; Moiseenkov, A.; Waili, I.H.; Niyadi, F.; ALRamidhi, Y.; Al Farei, I.; Nabhani, Y.; Lukmanov, R.B.; Al-Hashemi, M.; et al. Evaluation of hydraulic fracturing effectiveness by combined analysis of spectral noise logging and high precision temperature logging data and subsequent numerical temperature modelling. In Proceedings of the SPE International Hydraulic Fracturing Technology Conference and Exhibition, Muscat, Oman, 16-18 October 2018.

20. Zhang, P.; Lu, S.; Li, J.; Chen, C.; Xue, H.; Zhang, J. Petrophysical characterization of oil-bearing shales by low-field nuclear magnetic resonance (NMR). Mar. Pet. Geol. 2018, 89, 775-785. [CrossRef]

21. Sun, T.; Yan, W.; Wang, H.; Golsanami, N.; Zhang, L. Developing a new NMR-based permeability model for fractured carbonate gas reservoirs. J. Nat. Gas Sci. Eng. 2016, 35, 906-919. [CrossRef]

22. Lewis, R.; Singer, P.; Jiang, T.; Rylander, E.; Sinclair, S.; Mclin, R.H. NMR T2 distributions in the eagle ford shale: reflections on pore size. In Proceedings of the SPE Unconventional Resources Conference-USA, Woodlands, TX, USA, 10-12 April 2013. 
23. Morriss, C.; Rossini, D.; Straley, C.; Tutunjian, P.; Vinegar, H. Core analysis by low-field NMR. Log Anal. 1997, 38, 84-95.

24. Dejam, M. Advective-diffusive-reactive solute transport due to non-Newtonian fluid flows in a fracture surrounded by a tight porous medium. Int. J. Heat Mass Transf. 2019, 128, 1307-1321. [CrossRef]

25. Dejam, M.; Hassanzadeh, H.; Chen, Z. Semi-analytical solution for pressure transient analysis of a hydraulically fractured vertical well in a bounded dual-porosity reservoir. J. Hydrol. 2018, 565, $289-301$. [CrossRef]

26. Hassan, A.M.; Mahmoud, M.A.; Al-Majed, A.A.; Elkatatny, S.; Al-Nakhli, A.R.; Bataweel, M.A. Novel Technique to Eliminate Gas Condensation in Gas Condensate Reservoirs Using Thermochemical Fluids. Energy Fuels 2018, 32, 12843-12850. [CrossRef]

27. Al-Nakhli, A.; Mahmoud, M.; Al-Badairy, H.; Alqam, M. Advanced study of pore structure and mechanical property change of tight sand due to thermochemical treatment. In Proceedings of the International Petroleum Technology Conference, Beijing, China, 26-28 March 2019.

28. Alghamdi, A.H.A. Experimental and Theoretical Study of Surfactant-Based Acid Diverting Materials; Texas A\&M University: College Station, TX, USA, 2010.

29. Sayed, M.A.; Al-Muntasheri, G.A. Mitigation of the effects of condensate banking: A critical review. SPE Prod. Oper. 2016, 31, 85-102. [CrossRef]

30. Hassan, A.M.; Mahmoud, M.A.; Al-Majed, A.A.; Al-Nakhli, A.R.; Bataweel, M.A.; Elkatatny, S. Mitigation of Condensate Banking Using Thermochemical Treatment: Experimental and Analytical Study. Energies 2019, 12, 800. [CrossRef]

31. Corey, A.T. The interrelation between gas and oil relative permeabilities. Prod. Mon. 1954, 19, 38-41.

32. Ibrahim, M.N.M. Two-Phase Relative Permeability Prediction Using a Linear Regression Model. Ph.D. Thesis, University of Missouri-Rolla, Rolla, MO, USA, 1999.

33. Hassan, A.; Mahmoud, M.; Al-Majed, A.; Alawi, M.B.; Elkatatny, S.; BaTaweel, M.; Al-Nakhli, A. Gas condensate treatment: A critical review of materials, methods, field applications, and new solutions. J. Pet. Sci. Eng. 2019, 177, 602-613. [CrossRef]

(C) 2019 by the authors. Licensee MDPI, Basel, Switzerland. This article is an open access article distributed under the terms and conditions of the Creative Commons Attribution (CC BY) license (http://creativecommons.org/licenses/by/4.0/). 